\title{
A Metodologia Mora no Tema: infância e cultura em pesquisa
}

Rita Ribes Pereira'

'Universidade do Estado do Rio de Janeiro (UERJ), Rio de Janeiro/RJ - Brasil

RESUMO - A Metodologia Mora no Tema: infância e cultura em pesquisa. Este texto tem por objetivo problematizar a relevância do tema na atividade de pesquisa, mais especificamente, na construção da metodologia. As Ciências Humanas e Sociais são ciências discursivas e a voz dos interlocutores - o pesquisador e a criança - têm ocupado a centralidade na construção metodológica. A proposta deste texto é ampliar esse debate deslocando o foco para um terceiro elemento crucial na constituição dessa alteridade e que, muitas vezes, é pensado de forma apartada da metodologia: o tema. A problematização é feita a partir da análise de cinco pesquisas do campo interdisciplinar dos estudos da infância e assenta-se na filosofia da Linguagem de Walter Benjamin e do círculo de Mikhail Bakhtin e Valentin Volochnov.

Palavras-chave: Infância. Cultura. Pesquisa. Tema. Metodologia.

ABSTRACT - The Methodology Dwells on the Topic: childhood and culture in research. The following text discusses the relevance of the subject in the research activity, specifically when the construction of a methodology is concerned considering that Human and Social Studies are indeed discursive science and the interlocutors' voices - researcher and child - have been central to methodological construction. The text purpose is to broaden such debate, shifting the focus to a third crucial element in this otherness constitution that, very often, is considered apart from the methodology: the topic. The discussion is made from the analysis of five researches in the interdisciplinary field of childhood studies and based on philosophy of the language by Walter Benjamin and also Mikhail Bakhtin and Valentin Volochnov's circle.

Keywords: Childhood. Culture. Researcher. Topic. Methodology.

Educação \& Realidade, Porto Alegre, v. 46, n. 1, e106860, 2021. 
A Metodologia Mora no Tema

Este texto tem por objetivo problematizar a centralidade do tema na atividade de pesquisa, mais especificamente, na construção da sua metodologia, elemento que, muitas vezes, se mostra secundarizado ou, mesmo, desconsiderado. Para essa problematização apresentamos, brevemente, cinco projetos de dissertação e tese desenvolvidos no Grupo de Pesquisa Infância e Cultura Contemporânea para, a partir deles, lançar um olhar sensível sobre o lugar que o tema ocupa na construção da metodologia. São pesquisas produzidas no campo interdisciplinar dos estudos da infância e se inscrevem no debate acerca da especificidade da pesquisa com crianças.

A análise proposta se pauta na filosofia da linguagem que compreende a pesquisa como produção discursiva, sobretudo nas Ciências Humanas e Sociais, quando o objeto é também um sujeito que tem voz e se coloca em diálogo. Nesse diálogo, a voz dos interlocutores - o pesquisador e os seus outros, que aqui, especificamente, são as crianças - tem ocupado significativa relevância nos debates acerca da produção metodológica da pesquisa e dos princípios éticos que a sustentam. Registrase no texto de pesquisa o que especificamente as crianças disseram ou fizeram ou relata-se os diálogos entre os pesquisadores e as crianças de modo mais relacional e dialógico. Via de regra é em torno a essa alteridade $e u$-tu que se desenham as estratégias metodológicas visando organizar e sistematizar a comunicação verbal, por vezes, lançando mão de uma paleta de estratégias já tornadas clássicas nos manuais de iniciação científica - observação, questionários, entrevistas -, por outras, construindo estratégias que se adequem à especificidade do interlocutor - brincadeiras, oficinas, desenhos, etc.

É comum que o tema e a metodologia acabem por se desenvolver em separado no trabalho de pesquisa, ficando o estudo do tema como um trabalho estritamente teórico que se coloca em paralelo à construção metodológica. É recorrente, por exemplo, que se reserve, nas teses, dissertações ou artigos científicos, um capítulo ou seção dedicados especificamente à relação do pesquisador com o tema, a uma revisão de literatura ou mesmo a um estado da arte acerca do tema no contexto da produção de conhecimento. Em que pese a importância e o trabalho de fôlego que tais estudos demandam, o que estamos colocando em questão é que é possível que o tema da pesquisa, nessa abordagem apartada, seja expropriado da sua fertilidade em termos metodológicos, posto que à metodologia reserva-se uma outra seção e/ou tipo de abordagem.

O propósito deste texto é problematizar a centralidade do tema nas opções teórico-metodológicas de pesquisa, concebendo o tema como um terceiro elemento crucial na constituição da relação de alteridade entre o pesquisador e o seu outro, que aqui, especificamente, trata-se do pesquisador e a criança. Se pesquisador e criança são o $e u$ - $t u$ da relação de interlocução, o tema é o ele de quem se fala. O tema é o ele que cria a relação $e u$-tu. O tema tem parte ativa - e não passiva - no diálogo. Alterando-se o tema, altera-se toda a relação. Ele põe, (in)dispõe, faz falar ou silenciar. Tema-vertigem. Tema-desejo. Tema-moda. Tema-dever. Tema-tabu. O tema é para aqueles que se colocam em diálogo com ele. Não há diálogo sem tema. Nossa intenção, ao trazê-lo para uma con- 
dição de centralidade neste debate, não é de apartá-lo assepticamente da relação viva que mantém com os interlocutores ou tecer entre eles qualquer hierarquia, mas, sim, de chamar a atenção para o tema como elemento que instaura e disputa ativamente as condições do discurso.

Tal concepção se fundamenta na filosofia da linguagem do círculo bakhtiniano que assevera que toda produção discursiva implica necessariamente a presença de um locutor, um ouvinte e o tema em torno do qual se revezam na interlocução (Bakhtin; Volochinov, 2006). É o tema que funda a interlocução, e os sujeitos, na interlocução, posicionam-se valorativamente sobre o tema, sobre si e uns sobre os outros. Neste texto, especificamente, trataremos da pesquisa com crianças, o que demarca que essa tríade, na discussão que se segue, é constituída pelo pesquisador, pela(s) criança(s) e pelo tema que os coloca em conversação. Isso implica dizer que, valorativamente, esse diálogo, em sua base, produz e disputa concepções de infância e adultez. Que infâncias são produzidas pelo discurso científico? Como esse tema adquire relevância no saber científico? Que lugar ocupa a criança nesse saber?

O tema é componente da comunicação verbal, o organizador da fala e, portanto, da interlocução. É a matéria prima da enunciação, o conteúdo que mobiliza a interlocução amalgamado às formas do discurso. Articulando estrutura e superestrutura, compõe-se de fragmentos da realidade social materializados na linguagem. Se por um lado, é condição para a interlocução, por outro, sua permanência instável e sua significação efêmera são fundamentais para o fluxo da linguagem. (Bakhtin; Volochinov, 2006; Boenavides, 2015). O tema vincula-se à perspectiva semântica e está ligado aos sentidos verbais e não verbais da linguagem, eminentemente valorativos e ideológicos, posto que é determinado pelas formas linguísticas e também pelo contexto extraverbal. Inclui os ditos e não ditos.

Se o tema instaura a interlocução, são os interlocutores que zelam pela permanência ou evanescência do tema, e mesmo, um do outro, alternando-se na interlocução ou encaminhando o seu fim. Aqui parece tomar forma a ideia de uma metodologia em seu sentido embrionário, como arte de instaurar e manter uma conversação. E o que é a metodologia na atividade de pesquisa senão isso?

Essa condição discursiva baliza tanto os mais simples encontros cotidianos, a exemplo de um cumprimento, um muxoxo ou uma informação, quanto os mais complexos e especializados debates, como a teoria da relatividade ou a polifonia na obra de Dostoiévski. Bakhtin e Volochinov utilizam os termos tema e conteúdo temático a fim de pontuar uma distinção entre gêneros discursivos. Ao mesmo tempo em que os autores evitam fazer entre estes conceitos qualquer hierarquização e primando pela manutenção do tensionamento entre eles, percebe-se que o conceito de conteúdo temático recebe uma certa crítica na medida em que aparece referido a um tipo de fazer científico que tende a virar as costas para o mundo da vida cotidiana.

A preocupação de Bakhtin; Volochinov (2006) assemelha-se à que Walter Benjamin (2009) dirige à pedagogia colonial: no afã de preparar 
A Metodologia Mora no Tema

as crianças para a vida adulta, seleciona na cultura os temas que lhes considera imprescindíveis para apresentá-los adequadamente sob a forma de conteúdo escolar. Nesse processo de adequação, pondera Benjamin, resulta uma artificialidade que impede o tema de ser reconhecido como cultura. Nessa ótica, a cultura se aniquila enquanto o processo escolar se esvazia de sentido. Uma educação que considere o contexto é o contraponto político necessário apontado pelo autor.

Trata-se do mesmo mote do clássico texto Arte e responsabilidade, escrito por Bakhtin (2003): vida e arte, ou vida e ciência, podem manter entre si uma relação ética de respondibilidade mútua ou apenas uma relação mecânica. Se a ciência (ou a arte) se distancia da vida, seus enunciados cada vez mais abstratos se desvanecem e fragilizam a comunicação. O mesmo se dá se a vida cotidiana abdica de elaborar sistematicamente as suas problemáticas. Parafraseando Bakhtin, o cientista deve saber que sua ciência é responsável pela trivialidade da vida, assim como os homens e mulheres na sua vida cotidiana, com suas exigências ou abdicando delas, são responsáveis pela potência ou pela esterilidade da ciência.

Talvez o desafio ético posto por Bakhtin (2003) e por Benjamin (2009) esteja não apenas na tarefa de manter azeitado o diálogo/tensionamento entre a vida e a ciência, mas também na chamada de atenção para ver que a vida não é apenas uma problemática a ser resolvida, ou um conteúdo a ser abstraído. Um olhar mais atencioso para o tema permite ver que, dentre as enunciações que ele evoca, há uma extensa paleta de concepções de mundo, de ciência, de relações, de metodologias. O tema é sempre o mundo, vasto mundo, o assunto sobre o qual se fala ou se cala; o tema é, inclusive, quem fala e quem cala. Um tema não nasce no vazio, mas num contexto de indivíduos situados no tempo e no espaço. Nasce no mundo social e cultural e a ele se dirige.

\section{O Tema e o Nascer de uma Pesquisa}

Se o leitor aceitar o convite de pensar por um momento como se deu a escolha do tema de sua pesquisa - a primeira, a atual, a por vir talvez tenha dificuldade de dizer, ao certo se, efetivamente, escolheu o tema, ou se foi escolhido por ele. Do mesmo modo, numa pesquisa finda, o pesquisador segue marcado por seu tema. Pode acontecer de querer se despedir do tema ou até mesmo se libertar dele para lançar-se a novos horizontes e... lá segue o tema, amalgamado ao pesquisador, como uma espécie de segunda pele, uma identidade. Em situações simples como estas é que se torna possível perceber que, embora tratado como objeto pelo pesquisador, o tema dá a ver que é também um sujeito muito ativo, voluntarioso, revanchista até.

O nascer de uma pesquisa é um acontecimento que se dá no interior da ordem discursiva e instaura fluxos de linguagem. O tema aparece aos olhos do pesquisador como visagem ou fantasmagoria, para lançar mão de termos benjaminianos (Benjamin, 2006). É essa condição de fantasmagoria, aquilo que se mostra obscuro, a imensidão do que ainda se está por conhecer que faz nascer o pesquisador. E este, uma vez fis- 
gado pelo tema, passa a espreitá-lo, amalgamar-se a ele, e às vezes, até ser escravizado por ele. É o tema que dá origem ao diálogo. O tema em si não tem autor nem autoria. A autoria se desenha na forma de lidar com o tema e no exercício da argumentação. É como alguém que argumenta sobre um tema que o pesquisador instaura sua pesquisa e se torna seu autor, autoria que pode compartilhar e até mesmo perder se abdicar do lugar de responder ao tema para mantê-lo vivo no fluxo da linguagem.

Se é o tema que instaura a interlocução, há que prestar-lhe atenção, não para dominá-lo ou colonizá-lo, mas no sentido de sensibilizarse a ele no modo como se apresenta na vida. Walter Benjamin (1970) há muito assevera que a modernidade tratou de esmaecer a simplicidade da relação direta com as coisas na medida em que pautou o conhecimento sob a égide de um sujeito eminentemente epistêmico e supostamente atemporal. Em seu Programa para uma filosofia vindoura, o autor chamava a atenção para a urgência de se colocar o problema do conhecimento sob novas bases que levassem em conta a singularidade da experiência. Direcionava sua crítica às teorias do conhecimento de caráter eminente explicativo, e também ao campo da educação, que, com sua ânsia de transformar a cultura em conteúdo escolar, extirpa a cultura da relação com a vida cotidiana e a reapresenta artificialmente às crianças, já desfigurada, como protótipo de um saber instrumental.

A simplicidade da relação imediata com o mundo físico e social é o mote que nos conduz a pensar/viver o tema como morada da metodologia num projeto de pesquisa que tenha por objetivo aprofundar a experiência humana da realidade social. É um pensar/viver o tema por dentro do tema, colado a ele, nele, uma experiência de caráter estético que baliza uma postura outra de pesquisa. Isto não implica em negar uma epistemologia, ao contrário, a expande, na medida em que a coteja no diálogo com as dimensões éticas e estéticas que envolvem o conhecimento, relação imprescindível para uma ciência que se protenda $h u$ mana e que não vire as costas para a vida cotidiana.

Não há tema que não esteja situado na cultura e na realidade social. Quando o tema nos afeta, ele exige de nós a construção de uma sensibilidade que, na esteira do que apregoa Benjamin (2006), está mais em nos deixarmos tocar pelo tema do que em lançarmo-nos arvorosamente a ele, cercando-o para fazê-lo falar. Está em jogo colocar em xeque os limites de uma consciência empírica que se sustenta na ideia de um sujeito psicológico que organiza um conhecimento produzido no terreno da exterioridade. Um tema emerge como uma grandeza em face da qual é preciso, primeiro, calar-se, sentir, perceber os tempos e idiomas em que se comunica. Isso exige abdicar de uma postura armada e ansiosamente explicativa e embrenhar-se numa atividade quase mimética de compreensão de suas leis internas.

Walter Benjamin (2005, p. 80) trata disso no fragmento Caçando Borboletas, onde apresenta o jogo que se dá entre um menino e uma borboleta, jogo de bailado e disputa que se oferece como metáfora para entender as leis do idioma alheio no qual a borboleta e as flores se comunicam diante dos seus olhos, uma linguagem primordial e com semântica própria. Diz o autor:

Educação \& Realidade, Porto Alegre, v. 46, n. 1, e106860, 2021. 
A Metodologia Mora no Tema

Salvo viagens ocasionais no verão, instalávamo-nos anualmente, antes de eu ir para a escola, em casas de veraneio nas redondezas. Durante muito tempo o que delas me fazia recordar era a caixa espaçosa na parede de meu quarto, com os primórdios de uma coleção de borboletas, cujos exemplares mais antigos foram capturados no Jardim de Brauhausberg. Piérides da couve com bordas gastas, mariposas cor de enxofre com asas muito brilhantes, relembravam as ardorosas caçadas que tão frequentemente me atraiam dos caminhos bem cuidados do jardim para lugares ermos, onde me defrontava impotente com a conjuração do vento e dos perfumes, das folhagens e do sol, que possivelmente comandavam o voo das borboletas. Esvoaçavam em direção a uma flor, pairavam sobre ela. Com a rede levantada esperava tão só que o encanto que parecia se operar da flor para aquele par de asas cumprisse sua tarefa; então aquele corpo frágil escapava para o lado com suaves impulsos para imediatamente sombrear, imóvel, outra flor e, quase no mesmo instante, abandoná-la sem tê-la tocado. Se uma vanessa ou uma esfinge que comodamente podia ter alcançado, zombasse de mim com vacilações, oscilações e flutuações, então teria querido dissolver-me em luz e em ar a fim de me aproximar da presa sem ser notado e poder dominá-la. E esse desejo se fazia tão real que lufavam sobre mim, que me irrigavam, cada agitar e cada oscilar de asas, pelos quais me apaixonava. Entre nós começava a se impor o antigo estatuto da caça: quanto mais me achegava com todas as fibras ao inseto, quanto mais assumia intimamente a essência da borboleta, tanto mais ela adotava em toda ação o matiz da decisão humana, e, por fim, era como se sua captura fosse o único preço pelo qual minha condição de homem pudesse ser reavida. Contudo, mesmo quando já a resgatara totalmente, era-me árduo percorrer o caminho entre o palco de minha ditosa caçada e minha base, onde, de um tambor de herborista, iam surgindo éter, alfinetes de cabeça colorida e pinças. E em que estado ficara aquele território às minhas costas: o capim vergado, as flores pisoteadas; ainda por cima, o caçador havia lançado seu próprio corpo atrás da rede. E apesar de tanto estrago, tanta deselegância e violência, a borboleta assustada permanecia trêmula e, contudo, cheia de graciosidade, numa dobra da rede. Era desse modo penoso que penetrava no caçador o espírito daquele ser condenado à morte. O idioma no qual presenciara a comunicação entre a borboleta e as flores - só agora entendia algumas das suas leis. Sua volúpia sanguinária diminuía à medida que crescia sua confiança. No entanto, o ar no qual se movimentava aquela borboleta está hoje impregnado por uma palavra que, há dezenas de anos, nunca mais ouvi nem pronunciei. Ela conservou o insondável com que as palavras da infância fazem frente aos adultos. O longo estado de silêncio as transfigurou. Assim, naquele ar preenchido pelas borboletas, vibra a palavra Brauhasberg. No Brauhasberg, próximo a Potsdam, tínhamos nossa casa de veraneio. Mas o nome perdeu toda a gravidade, já não contém ves- 
tígios da cervejaria e é, em todo caso, um monte cercado de azul, que surgia no verão para abrigar a mim e a meus pais. E por isso a Potsdam da minha infância jaz num ar tão azul, como se as bruxas e almirantes, as de olhos de pavão e as da aurora estivessem espalhadas na superfície esmaltada de uma porcelana de Limoges, na qual sobressaem no fundo azul as ameias e as muralhas de Jerusalém.

A longa citação literária num texto acadêmico é, em si, um portal a partir do qual se espreita as leis do idioma alheio. Meninos e borboletas desenham com seu bailado de caça e fuga leis próprias de tempo, espaço e de deslocamentos que mais tem a ver com a intensidade da percepção do que com a extensão e suas métricas. Alguns pontos nos interessam de forma mais amiúde no fragmento de Benjamin: a relação entre o menino e a borboleta, o idioma da infância como primordial e o conhecimento como exercício de encantamento.

Em sua caçada o menino vai assumindo cada vez mais os movimentos e os modos de ser da borboleta, quase que transformando-se nela; a borboleta, para escapar, adota a astúcia do menino. O que está em jogo é entender as leis do idioma alheio no qual a borboleta e as flores se comunicam diante dos seus olhos. Um exercício de produção de semelhanças a partir do qual, de forma extrassensível, se adentra as leis internas de uma linguagem primordial e com semântica própria:

Zombando da criança o inseto oscilava, flutuante. Ao esvoaçar diante de uma flor e pairar sobre ela, o menino, com a rede levantada, esperava apenas que 'o encanto, que parecia se operar da flor para aquele par de asas, cumprisse sua tarefa'. Mas, em seu 'corpo frágil, a borboleta escapava com 'suaves impulsos' e logo ia 'sombrear imóvel' outra flor, abandonando-a rapidamente sem tê-la tocado. A criança ansiava 'dissolver-se em luz e ar' para aproximar-se de sua presa sem ser notada. Um desejo tão real que cada agitar e oscilar de asas lufava sobre ela, irrigando-a e deixando-a apaixonada (Castro, 2009, p. 206).

Destacando o caráter mimético que desenha esse bailado, Cláudia Maria Castro (2009, p. 206-207) lembra-nos que para Benjamin,

[...] talvez não exista nenhuma função superior do humano que não seja, decisivamente, codeterminada por esta faculdade mimética que tem na brincadeira infantil a sua escola. Nos jogos infantis, impregnados de comportamentos miméticos, as crianças imitam pessoas, mas também imitam coisas. [...] Como esse poder de imitação não se resume a uma reprodução passiva da realidade já dada, mas constitui uma verdadeira atividade de intercâmbio entre o mundo e o homem que se expressa, a semelhança que essa faculdade produz é imaterial.

Na perspectiva benjaminiana, o conceito de mimese, alicerçado nos saberes do mundo antigo, se sustenta na ideia de que a natureza e o extenso mundo físico são também sujeitos de ação. Tal perspectiva, de caráter ontológico, se esmaeceu com o advento da modernidade e a 
emergência de uma ciência hegemônica cujo centro é um sujeito eminentemente epistêmico que visa unilateralmente transformar o mundo (físico, social, cultural) em objeto e explicá-lo com sua razão analítica. Nesse contexto, a faculdade mimética tende a migrar para a linguagem, onde o signo procura assumi-la como tarefa, sobretudo na escrita.

A faculdade mimética, no entanto, é uma faculdade humana que resiste como um idioma da infância, com leis internas que se deixam ver nos jogos infantis onde as crianças, a natureza, as coisas habitam uma comunidade ontológica. E esta segue sendo a base de muitas culturas em suas diversas cosmologias e epistemologias que ainda hoje coexistem e/ou disputam reconhecimento social face à desigual hegemonia da ciência moderna. Benjamin, por exemplo, constrói sua teoria do conhecimento transitando entre elementos da cultura judaica, do empirismo delicado de Goethe e do que Michel Löwi (2005, p. 26) chama de um marxismo gótico, isto é, um “[...] materialismo histórico sensível à dimensão mágica das culturas do passado”.

Também a criança transita entre diferentes tipos e formas de saber, sem tecer entre eles hierarquia e reconhecendo-os nos seus contextos sociais e culturais. Um exemplo disso é trazido por Benjamin (2009, p. 107-108) em seu fragmento Criança escondida, onde o flerte com o animismo e antropomorfismo reveza com a lógica da engenharia:

Já conhece todos os esconderijos da casa e retorna a eles como a um lar onde se está seguro de encontrar tudo como antes. O coração palpita-lhe, ela prende a respiração. Aqui ela está encerrada no mundo material. Este mundo tornase extraordinariamente nítido para ela, acerca-se dela em silêncio. Assim, somente alguém que vai ser enforcado se dá conta do que significam corda e madeira. Atrás do cortinado, a própria criança transforma-se em algo ondulante e branco, converte-se em fantasma. A mesa de jantar debaixo da qual ela se pôs de cócoras, a faz transforma-se em ídolo de madeira em um templo onde as pernas talhadas são as quatro colunas. E atrás de uma porta, ela própria é porta, incorporou-a como pesada máscara e, feita um sacerdote-mago, enfeitiçará todas as pessoas que entrarem desprevenidas. Por preço algum ela deve ser encontrada. Quando ela faz caretas, dizem-lhe que basta o relógio bater as horas e a careta ficará para sempre. O que há de verdade nisso tudo a criança sabe-o em seu esconderijo. Quem a descobrir pode fazê-la petrificar-se como ídolo debaixo da mesa, entretecê-la para sempre como fantasma na cortina, bani-la pelo resto da vida na pesada porta. Por isso, quando é tocada por aquele que a procura, a criança deixa escapar com um forte grito o demônio que a transformaria, para que não seja encontrada - na verdade, nem espera por esse momento, antecipa-se a ele com um grito de autolibertação. Por isso ela jamais se cansa da luta com o demônio. Nessa luta a casa é o arsenal das máscaras. Contudo, uma vez por ano, [deixam-lhe] presentes em lugares misteriosos, nas órbitas vazias dos olhos, na severa boca da casa. A mágica experiência torna-se ciên- 
cia. Como seu engenheiro, a criança desencanta a sombria casa dos pais e procura ovos de Páscoa.

Em seu mimetismo, a criança retém a fisionomia do mundo (Castro, 2009). Talvez seja esse o desafio do pesquisador: reter do tema a sua fisionomia. Isto exige compreender o tema como sendo também um sujeito ativo na construção do conhecimento e não apenas um objeto submisso aos protocolos do pesquisador. Quando um tema instaura interlocução na forma de uma pesquisa, mais que cercar o tema, tal qual engenheiro afoito que traça em sua planilha um mapa na busca dos ovos de Páscoa, o chamamento feito ao pesquisador é o de, primeiro, entrar no jogo que transforma seu tema num distrito com linguagens e leis próprias. É aqui, justamente aqui, que se mostra o nascedouro de uma metodologia de pesquisa, o balbuciar de um idioma de infância, condição para a produção de uma ciência sensível, sem o que, como asseverara Benjamin (2009), corremos o risco de petrificar caricatos ao bater as horas.

A metodologia ganha forma na ação do pesquisador de produzir semelhanças entre sua pesquisa e o tema tal qual ele se mostra na vida cotidiana. Essa tarefa não se distingue daquela em que os seres humanos, olhando no céu um amontoado de estrelas, produziram entre elas semelhanças estéticas imateriais criando o que nomeiam como constelações. O mesmo que sucedeu com o menino e a borboleta, que no instante da caçada, revezam semelhanças. Trata-se da produção de um tipo de semelhança próprio da faculdade mimética, que Benjamin (1985), em seu texto A doutrina das semelhanças, conceitua como semelhança extrassensível, de caráter imaterial e invisível, que "[...] não se resume à uma reprodução passiva da realidade já dada, mas constitui uma verdadeira atividade de intercâmbio entre o homem e o mundo que se expressa" (Castro, 2009, p. 207).

Benjamin (1985, p. 110) pondera que, sendo a semelhança extrassensível do campo das percepções que não se fixam, pois se mostram num relampejo, ela tem um tempo próprio em que pode ser percebida em ato, ou, como nos facilita Castro (2009), em que ela pode ser agarrada, a exemplo do que acontecera com o menino e a borboleta: a semelhança produzida tem a exclusiva duração do embate e, depois dele, pode até ser evocada como memória, mas apenas ali, no embate, se produziu como semelhança. Há um jogo de encantamento e de desencantamento, onde, por vezes, o tempo é o da evasão e do entregar-se e, por outras, o tempo é o da perspicácia de capturar o relampejo enquanto ainda não se esvai. O que está em jogo é a retenção da sua fisionomia - o modo como se mostra e sob o qual permite ser olhado.

Estas ponderações parecem importantes para o desenhar da metodologia da pesquisa. Que tipo de relação o pesquisador constrói com seu tema? Em que bases constrói a sua percepção? Que semelhanças extrassensíveis são possíveis ao pesquisador no instante de sua pesquisa? Qual o tempo para apreendê-las, se não duram mais que um relampejo? Mais que chegar ao tema, etapa de pesquisa já bastante explorada nos relatórios, urge experienciar ser com o tema, o estar com o tema, enunciar de dentro dele. Ocupar sua pesquisa como quem se metamorfoseia

Educação \& Realidade, Porto Alegre, v. 46, n. 1, e106860, 2021. 
em criança escondida, que domina seus esconderijos como um lar, mas que na busca dos presentes de Páscoa age como um engenheiro, parece ser a lição oculta que Benjamin nos lega em seus fragmentos. Brincar de esconder-se para deixar o tema se mostrar.

Mimetizar-se com o tema, metamorfosear-se nele, sentir-se parte dele, ou, dito de outro modo, relacionar-se com o tema sob a ótica da simplicidade:

[...] deixar que ele comunique, que ele mostre como toca e é tocado pelo tempo e pelo espaço do dizer, as condições em que se revela, em que afeta, em que coloca em jogo a sua sensualidade. A primeira escuta de uma pesquisa é para o seu tema, pois ele guarda os segredos do tempo e do espaço que desenham o encontro. É preciso deixá-lo mostrar as linguagens em que se permite abordar, o ritmo próprio que ele tem no fluxo da vida (Schubski et al., 2018).

É no tema que se tece a alteridade entre o pesquisador e o seu outro. E, neste caso, nas pesquisas do campo interdisciplinar de estudos da infância, o outro-criança tem muito a ensinar ao pesquisador - tanto as crianças que porventura sejam os interlocutores da pesquisa, quanto pela infância que habita o pesquisador enquanto experiência e memória. O idioma da infância, portanto, não lhe é estrangeiro, ainda que possa lhe soar unicamente exteriorizado.

\section{A Infância como Tema, a Infância em Temas}

Há sempre uma concepção de infância que permeia a escolha do tema e, também, uma concepção sobre o que deva ser a pesquisa com as crianças. Essa concepção se mostra na escolha da infância como tema e na justificativa da sua realização. Antes mesmo da criação de um projeto específico, pesquisar infância - na sua condição de experiência - e/ ou pesquisar com crianças na sua condição de categoria social e geracional - implica assumir a infância como um tema primeiro. Junto disso, há uma ética que se desenha naquilo que supomos ou intuímos ser a infância, que se altera no encontro em campo, que se reafirma na divulgação nos resultados. Em que a infância afeta o pesquisador para que se transforme em tema para ele? Por que escolhe esse tema e não outros? Escolhe a infância como tema para quê?

Compreendendo que a infância é um tema primeiro, um tema fundante para toda pesquisa que envolve crianças e infâncias, vale destacar que qualquer outro tema tomado para estudo se consubstancia ao tema da infância de maneira relacional. Quando a infância, como tema, instaura uma pesquisa, a que temas se aproxima, de que outros se afasta? Que temas ganham hegemonia? Que temas são silenciados? Que temas as pesquisas com crianças têm colocado em debate? Quais desses temas emergem propostos pelo pesquisador? Que temas emergem através das crianças? Que temas elas demandam? Que temas evitam? São muitas as questões que emergem quando se traz o tema para a centralidade da interlocução. 
Em nossa trajetória de pesquisa, temos percebido que é uma abertura incondicional e quase mimética que dá a ver que cada tema, na sua singularidade, pede uma forma própria de tratamento, uma metodologia, na medida em que ele tem uma forma própria de ser, de fertilizar a pesquisa ou evadir-se dela. Nesse sentido se torna artificial pensar metodologias a priori como quem desenha num estêncil vasado que permite aplicação de diferentes tintas em diferentes paredes... É a sensibilidade ao tema, o entregar-se a ele e suas linguagens, que faz com que cada pesquisa seja $u m a$, única, irrepetível em sua metodologia (Schubski et al., 2018) e concepção.

Dialogar com o idioma do tema, habitar seus espaços, sentir o seu ritmo, reter sua fisionomia etc. são experiências imprescindíveis à concreção de uma metodologia. Delas se extrai a teorização necessária e o caráter autoral da pesquisa. Não se trata, porém, de tarefa fácil, e uma primeira dificuldade talvez esteja em se deixar tocar pelo tema com simplicidade. Onde e quando nasce a pesquisa? É exatamente aí que o tema se oferece como esconderijo e chama para a conversa. Em que linguagem ele chama? Que ritmo de tempo solicita? Que tipo de atenção requer? Qual sua dinâmica? O que, dessa dinâmica, se mostra como protótipo para uma estratégia metodológica?

Apresentamos a seguir algumas pesquisas desenvolvidas no Grupo de Pesquisa Infância e Cultura Contemporânea. A intenção é apresentá-las dando visibilidade à centralidade do tema na construção da metodologia. São trazidas como exemplares na ótica da simplicidade, que é comum quando se recorre a um exemplo para dar materialidade àquilo de que se fala. Não têm a pretensão de se oferecerem como modelo, o que o próprio argumento teórico deste texto torna impossível. São relatos resultantes de estudos, de diálogos e do enfrentamento de dilemas que se colocam ao pesquisador no processo da pesquisa. $\mathrm{Ob}$ servar a preponderância do papel do tema na construção da metodologia ou estar atento às nuances da relação do pesquisador com o seu tema nem sempre são experiências possíveis de serem percebidas pelo pesquisador enquanto está imerso no processo da pesquisa. Muitas vezes é quando o texto finalizado ganha alteridade na leitura que essa centralidade do tema vem à tona - e não raro, para mostrar que havia outros caminhos mais fecundos.

Estamos aqui reafirmando a importância de exercitar um diálogo alteritário sobre os processos de pesquisa ainda na sua condição processual, em ato. Aqui, vale destacar o caráter formador dos grupos de pesquisa que podem propiciar essa alteridade crítica aos seus membros ao longo do processo. É essa alteridade que transforma pequenos dilemas particulares em profundas questões de pesquisa que formam, que educam o grupo, como grupo, para a construção de epistemologias avessas à colonialidade. É nessa perspectiva que este texto é escrito no plural. É é com esse tom que queremos trazer alguns exemplos do que estamos falando, situações particulares de pesquisa que, no diálogo, se engrandecem como questões coletivas. Estudos cujos temas centrais são: crianças e redes sociais online, crianças em vídeos virais, aniversários de crianças, criação musical de crianças e crianças nas rodas de samba. 
A primeira pesquisa que trazemos tem por tema as redes sociais, mais especificamente, Orkut e Facebook, é a Tese de Doutorado de autoria de Nélia Mara Rezende Macedo $(2014)^{1}$. O tema emerge no contexto escolar com crianças em fase de alfabetização conversando sobre postagens que compartilharam no Orkut. A professora se esforça para entrar na conversa e o que recebe em resposta é uma pergunta direta "Você tem Orkut?". Tal pergunta soa como pedido de uma senha de acesso, sinalizando que o assunto de que tratavam não seria compreendido de fora. $\mathrm{O}$ tema, que emerge alçando a professora à condição de pesquisadora, indica ter ambiente e linguagem próprios: a rede social online. Objetivando conversar com as crianças sobre os usos que faziam das redes sociais, a pesquisadora, atenta a essa verdade sutil, foi desenhando sua metodologia de pesquisa no uso. Criou chats privados com crianças que já eram suas amigas e desenvolveu sua pesquisa - agora no Facebook - sob duas frentes de trabalho: observar os perfis das crianças - o que postam, o que curtem, o que comentam, o que compartilham - e uma conversa mais amiúde através desses chats.

Vez ou outra, as crianças voltavam a sinalizar os usos da linguagem que são próprios desse ambiente. Se a pesquisadora usava o espaço dos chats para comentar alguma postagem feita por elas, reclamavam do fato da pesquisadora não ter feito tal comentário no lugar que a rede social reserva para os comentários - como o próprio nome indica. Às conversas mais demoradas, avisavam que no Face as conversas são, literalmente, mais abreviadas. A pesquisadora foi alternando deslocamentos seus mobilizados pelas indicações das crianças com provocações que fazia na intenção de saber e de provocar um uso crítico - comentários, por exemplo, sobre os critérios para fazerem amigos online, se suas postagens eram públicas ou vistas apenas por amigos online, postagens de fotografias, o que costumavam dizer quando comentavam e como lidavam com o que era dito a elas nos comentários de suas postagens etc.

A maior ou menor familiaridade do leitor com a linguagem dos parágrafos anteriores dá a ver que o tema dessa pesquisa (o tema de toda pesquisa) já oferecia caminhos para a sua exploração e que eles foram se mostrando à pesquisadora à medida em que ela se permitia aproximar-se dele (o tema), não no afã de dominá-lo, mas de acompanha-lo no seu fluxo, para que ele pudesse se mostrar a ela na sua intimidade - o seu tempo, seu espaço, sua linguagem, seus segredos. É nesse terreno delicado que o tema põe à mesa as questões éticas da pesquisa. No caso, a questão central que se colocava era a criação de uma pesquisa com crianças no Facebook, quando esta rede social supostamente não se destinava às crianças. O jogo normativo que se estabelece entre a rede social e as crianças ajuda-nos a melhor entender o que estamos chamando de tema (o ele de quem pesquisadora e crianças tratam na condição de pesquisa): as crianças adulteram a idade para fazerem seus perfis na rede social; a rede social que, de acordo com esse critério, não é voltada para crianças, oferece, internamente, uma série de jogos pueris e comemora o Dia das Crianças. O tema pede pesquisa. Oferece caminhos. Convida para a leitura da Tese. 
Foi pedindo pesquisa que a temática dos vídeos virais ganhou existência na Dissertação de Mestrado de Perseu Pereira da Silva (2018). Vídeos virais são vídeos que circulam em proporção exponencial nas redes sociais e que num curto espaço de tempo somam milhões de visualizações - uma velocidade de contaminação, termo hoje tornado comum em tempos de pandemia. Entre os vídeos mais viralizados estão aqueles que estampam a imagem de crianças. Situações pueris, engraçadas, conflituosas, violentas etc. Intimidades. Exposições. O que faz a imagem da infância ser uma imagem viral? Em que termos a viralização da infância em vídeos contrasta com as prescrições de uso da internet pelas crianças, como mencionado na pesquisa anteriormente citada? Quando a infância evoca admiração, exposição, comoção, proteção, descuido, indiferença?

Acostumado com a lógica e a complexidade da produção de vídeos, Perseu estrutura seu trabalho de pesquisa organizando uma coleção desses vídeos que circulam e objetivando contatar crianças que se tornaram imagens viralizadas e os autores desses vídeos, aqueles que filmaram e/ou postaram originalmente essas produções. O ponto de partida de Perseu é a tese de que toda mídia, como produção discursiva, tem autoria e endereçamento. Mas as redes sociais, como ambiente de circulação desses vídeos, recolocam em questão essa tese. Paradoxalmente, a coleção cresceu em proporção exponencial e a tentativa de contato/diálogo com os autores desses vídeos ou com as crianças que os protagonizaram se mostrava, cada vez mais, um trabalho infértil, mesmo quando buscado através do canal onde o vídeo havia sido postado. Um olhar atento aos comentários que as plataformas disponibilizam nos vídeos dá a ver que estes, em grande parte, são feitos mais para marcar outras pessoas para verem os vídeos do que, propriamente, comentando ou problematizando o conteúdo de que tratam. Os vídeos se replicavam em memes, remixes e uma série de recriações, transitando e se replicando entre diversas plataformas - Youtube, Facebook, WhatsApp etc. - fazendo com que a imagem das crianças não cessasse de se multiplicar.

Aqui, vale paralisar o fluxo viralizante e retomar a discussão sobre o tema da pesquisa. Observemos que, enquanto a pesquisa anterior convidava a uma imersão sem limites no ambiente da rede social Facebook, a lógica dos vídeos virais, diferentemente, se mostra avessa a qualquer imersão. A postagem original não somente pode ser tecnicamente inacessível, como também, no fluxo dessa prática de viralização, tornou-se socialmente desnecessária. O tema exigiu do pesquisador tornar-se voyer de uma infinidade de vídeos, seja daqueles que ele acessava na condição de um pesquisador que organiza seu material de campo, seja, também, dos vídeos que passaram a ser compartilhados com ele na medida em que o seu tema de pesquisa se tornava público. Indicações que não cessam mesmo encerrada a pesquisa...

São duas pesquisas distintas que têm as tecnologias - e, mais especificamente, as redes sociais - como suporte para o seu acontecimento. No entanto, no distrito de seus diferentes temas e com suas leis in- 
A Metodologia Mora no Tema

ternas, encaminham a construção metodológica de maneira singular. Mas há que estar atento para extrair no âmago das questões técnicas a sua dimensão política: se é necessário ser usuário para poder dialogar com o tema, de dentro, o mesmo tema que instaura a pesquisa, paradoxalmente, também alimenta o mercado, e convoca a diferentes idiomas. O pesquisador não atento a isso pode não ultrapassar politicamente sua condição de usuário na interlocução, naturalizando o slogan de que as redes sociais são, por sua natureza, dialógicas. Há que indagar - de dentro - o que se está chamando de diálogo e suas reais possibilidades, quando, sob as leis internas do tema, ele floresce, ou quando, simplesmente, não cabe.

As relações entre a intimidade e a exposição também estão presentes na Tese de Núbia de Oliveira Santos (2013) que tem por tema os aniversários de crianças. Concebendo inicialmente o aniversário como marcação do tempo em relação à sua data de nascimento, objetivava conversar com crianças sobre o significado que essa data tem para elas. Quando o tema se mostra às crianças, no entanto, ele se redesenha: aniversário é festa. É a festa que sinaliza o aniversário. Pesquisar aniversários de crianças, portanto, implicava pesquisar festas de aniversário. Tema com espaço, tempo, linguagem próprias. Mimetizar-se com o tema, neste caso, implicava estar nas festas. Mas como um pesquisador adentra uma festa de aniversário, ambiente da vida privada? Limitar-se aos convites que porventura chegassem? Arvorar-se como penetra? O que pede o tema?

Seguindo as leis da etiqueta desenhadas pelo tema, a pesquisadora construiu um caminho que visava a expansão dos limites do seu mundo social. Ia nas festas de crianças que já faziam parte de sua rede de amizade ou parentesco e, nessas festas, passou a falar de sua pesquisa e buscar formas de oferecer-se para ser convidada para as festas dessa rede que se formou a partir das crianças com as quais já convivia. Assim, adotada por essa rede, passou a frequentar diferentes festas, algumas em que o convite se justificou unicamente pela pesquisa e outras em que, pela recorrência da sua presença, elevou-a condição de amiga, incorporando-se à lista de convidados. Aqui, vale destacar, tanto a surpresa dos anfitriões com o inusitado do tema numa pesquisa, como as concepções de pesquisa que passaram permear os convites. Aos poucos a pesquisadora tornou-se aquela que não se pode esquecer de chamar. Mas também aquela de quem se espera que diga algo sobre a festa, já que é uma pesquisadora. E o que dizer de uma festa para aqueles que fazem a festa? Como locutores e ouvintes se revezam valorativamente sobre o tema? Como os contextos extraverbais redesenham o tema e a relação entre os interlocutores? Como ditos e não ditos disputam relevância? Se já tratamos das questões éticas que implicam a pesquisadora revestir-se da condição de convidada, agora cabe indagar em que a condição de convidada afeta a pesquisadora? O que pede o tema?

Uma festa de aniversário de criança não é só uma festa. Envolve os preparativos, a realização e seus desdobramentos, e, mais recentemente, um tema. A festa também tem seu tema. Convites, tema da festa, bolo, parabéns, animação, troca de presentes, lembrancinha etc. Cada 
item citado abre um portal para pesquisa. Convites verbalmente feitos. Bilhetes. Impressos. Manuscritos personalizados. Festas intimistas. Festas espetáculos. Festa na casa da criança, em casa de festas, na escola, no parque, no zoológico, no salão de beleza, na limosine. Temas inspirados na mídia, em conteúdos escolares, em profissões. Crianças organizando suas brincadeiras, animadores organizando as brincadeiras e as crianças. Brincadeiras espontâneas ou animadas para envolver os adultos. Presentes entregues em mãos para o aniversariante, presentes guardados pela família ou profissionais das casas de festa para entrega à criança depois de finda a festa. O Parabéns. Poses para fotos. Lembrancinhas para os convidados. Nessa extensa atividade que é uma festa, a metodologia da pesquisa, delineada pelo tema, abrangeu a observação de festas, conversas com crianças, análise dos temas escolhidos, dos convites, fotografias, lembrancinhas etc.

Difícil perceber nesta infinidade de itens, o afeto que mobilizou cada um. Do bolo feito em casa porque neste ano não vai dar pra ter festa ao bolo mais rebuscado, da mesa inexistente à mesa que mais ostenta, da festa imaginária à festa do mercado, há uma família - um alguém dizendo para a criança da sua importância. Difícil perceber, na sutileza destes limites o limite ético que se desenha para a pesquisadora. O que pode a convidada sair dizendo sobre a festa em que esteve? $\mathrm{E}$ a pesquisadora, pode sair calada? Entre o miudinho do afeto e a cultura do espetáculo, o tema se torna uma aporia, um campo minado, como certa vez lhe disseram. O tema exigiu eticamente uma delicadeza de trato que, sem negligenciar as contradições que atravessaram o processo, marcaram a forma de escrita e os resultados da pesquisa.

Delicadeza semelhante também foi exigida a João Lanzillotti da Silva, cuja Tese tratava da criação musical com crianças (2015). O estudo ganhou o status de pesquisa quando emergiu nas aulas de música em que atua como professor. Como se dá o processo de criação musical entre as crianças? Vale chamar a atenção ao fato de que essa pergunta em nada tem a ver com aquela que perguntaria como se ensina música às crianças. Neste caso, o tema exige que se coloque em cena condições para que as crianças vivam processos de criação com a linguagem musical - o que implica espaço, tempo, condições materiais específicas. E alguns desafios: como reconhecer uma criação? Como dizer o que não é? Como registrar esses processos?

Escutando as demandas do tema, o pesquisador adotou como metodologia a organização de uma oficina, oferecida no contraturno escolar. A chamada para participação tinha por proposta montar uma banda e colocava como critério inicial que os interessados soubessem tocar algum instrumento. Mas um tema jamais se oferece do mesmo modo à variedade dos seus interlocutores e a métrica do saber tocar ficou restrita à autodeclaração, formando, por fim, uma banda com crianças em diferentes níveis de conhecimentos musicais. O tema da criação deu o diapasão quando o pesquisador apresentou o projeto dizendo que teriam liberdade para organizar a oficina e a banda, mas que ao final do semestre gostaria que levassem alguma coisa produzida ali para participar de um evento da escola.

Educação \& Realidade, Porto Alegre, v. 46, n. 1, e106860, 2021. 
A Metodologia Mora no Tema

Músico e professor, o agora pesquisador escutava que o tema exigia tempo e não diretividade. E assim, fora levando os dias, deixando as crianças experimentarem instrumentos, buscarem músicas, trocarem letras e cifras, marcarem encontros fora dali etc. Numa fresta ou outra dessa rotina em que preferiu ficar mais calado e observando, flagrava, às vezes, algumas crianças comentando sobre arranjos, sugerindo um toque ou outro. Meses depois, as oficinas seguiram como um grupo de amigos que se encontra para tocar junto músicas que gostam. $\mathrm{O}$ pesquisador procurava ser um deles para não tolher os processos. A banda ia muito bem. Mas a pesquisa começava a preocupar João.

Essa sensação de ver o tempo passar e, aparentemente, a pesquisa não acontecer é um sentimento recorrente e que causa muita aflição aos pesquisadores. É que é difícil viver um processo e, ao mesmo tempo, pensar sobre ele. Vida e arte. Vida e Ciência. São diferentes ritmos de tempo e intensidades de ação. Mas, enfim, o que aconteceu enquanto se supõe não ter acontecido nada? Para repensar sua ação em campo, João escutou e transcreveu todos os ensaios da banda até então. Ouviu como se fosse outro, porque agora podia se ouvir também. Foi então que percebeu que sua voz pouco aparecia, atento que estava à liberdade das crianças para a criação - um cuidado ético que priorizou, num mundo tão ávido a dizer-lhes tudo em forma de ensinamento. Percebeu que as crianças tocavam repetidamente músicas que gostavam, mas que nessa repetição arriscavam mudar um arranjo, uma frase aqui, outra lá. Incluíam instrumentos não pensados no arranjo original. Consideravam que alguns erros deixavam a música melhor. Percebeu também que a criação não é algo espontâneo que aparecia sob o ímpeto de uma genialidade esporádica. As crianças concordavam com Vigotski! Era preciso primeiro conhecer variadas músicas para só depois criar, vaticinaram algumas. Mas outras se sentiram desde sempre confortáveis na condição autoral ao lhe dizerem olha o que eu fiz, com a mesma desenvoltura com que um dia afirmaram saberem tocar...

Voltando à banda - já com a escuta às crianças, a si, e ao tema - o que fez João? Foi tocar de ouvido, tocar junto como em alguns momentos já havia feito e intensificou a conversa e, sobretudo a escuta. Pois o que aprendera com o tema foi que é no minúsculo e quase imperceptível intervalo sonoro que uma troca de olhares reconhece um arroubo criativo - e as perguntas de pesquisa, se amalgamadas ao tema, são as perguntas da música, as demandas da banda. Não respondem em idioma estrangeiro. A metodologia mora no tema. Fragmentos desse processo foram selecionados entre as muitas horas de gravação e salvos em arquivos de mídia disponibilizados na internet e referenciados em nota de rodapé no texto escrito da Tese, para que o leitor possa acompanhar a narrativa do pesquisador sobre os processos de criação musical dessa banda, podendo escutá-los na linguagem em que a música se estrutura - o som.

A música também se faz presente na quinta e última pesquisa que aqui apresentamos. As crianças nas rodas de samba é o tema da Dissertação de Raíza Venas (2019). Assídua frequentadora das rodas de samba, um dos muitos movimentos negros de resistência e atualmente avilta- 
dos pela oficialidade carioca, a presença de crianças nessas rodas chamou a atenção da pesquisadora, interessada em aprofundar um estudo sobre as formas de participação das crianças nesses ambientes da cultura popular. Assim como na Tese de Nélia sobre os usos do Facebook, não estamos indagando sobre a pertinência ou não das crianças nas mais diversas formas de produção cultural. Temos como pressuposto teórico que o lugar da criança é a cultura e que elas, pela sua simples presença no mundo, instauram a sua participação. Uma vez partícipes do mundo social e cultural, interessa-nos dialogar com o seu ponto de vista e compartilhar sentidos ao mundo.

Num primeiro momento, mais do que procurar no tema - tão familiar - possibilidades metodológicas, o que apareceu aos seus olhos eram as impossibilidades. Como pesquisar num lugar abarrotado de gente e com som relativamente alto? Quem iria parar de sambar para participar de uma pesquisa? O tema, definitivamente, recusava o imaginário do pesquisador com sua prancheta. Ao contrário, pedia ginga e metodologias que não atravessassem o samba.

No projeto institucional ${ }^{2}$ ensaiávamos formas de observação do cotidiano que dispensassem a interlocução direta com as crianças e que se voltassem mais para o cenário das situações vividas por elas. Se até então a interlocução verbal pesquisador-criança havia sido uma abordagem central nas pesquisas do grupo e em torno do que dedicamos quase quinze anos de elaboração teórica, nossa intenção, no então novo projeto, consistia em construir um deslocamento do lugar do pesquisador em relação às crianças, uma postura que visava mais aquietar-se para substanciar a atenção do que propriamente arvorar-se à conversa, diretiva e propositivamente. Deixar que as crianças, no cotidiano, viessem a nos afetar em diferentes situações. Projetava-se observar com atenção essas situações, registrá-las e dar acabamento a esses registros sob a forma de crônicas, no intuito de expandir os gêneros discursivos do saber científico e contribuir politicamente para a popularização da ciência.

O fluxo de bolsistas de iniciação científica, mestrandos e doutorandos num grupo de pesquisa acontece em diálogo com o cronograma do projeto institucional do grupo. Por vezes, o estudante-pesquisador é beneficiado pelo fato de, ao chegar ao grupo, encontrar um arcabouço teórico ou arranjos metodológicos já consolidados que lhe oferecem uma certa segurança, ainda que relativa, mas, quando o grupo ensaia um novo projeto, é ele, muitas vezes, quem inaugura publicamente no debate acadêmico, com o seu trabalho, opções teóricas ou metodológicas ainda em gestação na coletividade do grupo. Este foi o caso de Raíza, que iniciou seu projeto de mestrado desafiada a avaliar a possibilidade de observar seu campo e registrar o vivido sob a forma literária de uma crônica.

Se por um lado, a proposta se afinava ao ritmo das rodas de samba, por outro, instigava a pesquisadora a pensar que, se no seu trabalho monográfico de graduação eram as vozes das crianças com quem dialogara que atestavam veracidade à sua pesquisa, sob que bases agora, esse critério da verdade se assentaria? A pergunta simples de Raíza co-

Educação \& Realidade, Porto Alegre, v. 46, n. 1, e106860, 2021. 
A Metodologia Mora no Tema

loca em debate a complexidade das Ciências Humanas e Sociais, com seus campos e metodologias, bem como o lugar de autoridade dos seus pesquisadores em face das disputas políticas por hegemonia de saberes. Quando o pesquisador se autoriza a enunciar tendo por critério sua coerência teórica e metodológica? Quando o pesquisador só se sente autorizado a enunciar sob a voz de um outro - seja a voz da criança ou de um autor de referência? Em que o fato de Raíza ser uma mestranda altera as condições do seu dizer? Há muitas sutilezas entre aquilo que o pesquisador se autoriza e a autoria do seu trabalho.

As métricas da ciência hegemônica - que é hegemônica justamente porque se internaliza em nós como um discurso único - assim como naquele fragmento de Benjamin (2009), se colocam prestes a bater as horas e nos flagrar numa careta amedrontada em forma de perguntas: pode o pesquisador criar os seus métodos e critérios de interpretação? Pode o pesquisador recusar a ideia de uma verdade confinada e assumila como busca e bússola? Há que se aprender com as crianças, em seus esconderijos, o jogo de querer ser achado - o que aqui tomamos como metáfora da participação ativa no debate acadêmico com nossos diferentes enunciados de pesquisa. E há, também, que se aprender com as crianças a se antecipar à fatídica captura - uma boa metáfora para o silenciamento e o apagamento das epistemologias não hegemônicas. Antecipar-se com um forte grito de autolibertação. Aqui se estabelece uma ética entre o pesquisador, sua pesquisa e a realidade social: é pelo argumento que ele afirma a sua autoria, defende suas escolhas e submete-se publicamente ao crivo do reconhecimento social.

Raíza construiu seu argumento sem alterar o samba tanto assim, como diz a música de Paulinho da Viola. Ao contrário, percebendo que a metodologia se oferecia no próprio tema, foi chegando, agora como pesquisadora, afinada aos elementos primordiais das rodas se samba. E de que é feito o samba? "É de gente! É de gente nova e de gente velha que se faz roda de samba! Salve as crianças! Licença aos mais velhos!". Anotando uma informação ou outra no celular sem deixar de sambar, fazendo fotografias panorâmicas para ajudar a memória que às vezes se abala após uma noite no samba, recorrendo à ajuda do povo do samba para alguma informação ou interpretação que julgasse incompleta, percebeu as crianças em diferentes formas de participação: as que sambavam nos pequeníssimos espaços que sobravam, as descontentes que foram sem querer ir, as filhas de trabalhadores que ajudavam seus pais ou dormiam nalgum cantinho enquanto seus pais trabalhavam, as crianças trabalhadoras vendendo balas em meio à apertada e compassada multidão, crianças que atazanavam os sambistas querendo tocar seus instrumentos, crianças que tocavam junto, crianças que já eram celebridades no mundo do samba. Escrever com ginga foi o jeito que Raíza encontrou de dar seu grito de autolibertação.

\section{Considerações Finais}

É da diversidade de temas e dos caminhos que se insinuam em cada estudo que extraímos a tese que intitula este texto: a metodologia 
mora no tema. Mas não se entrega de imediato. Há um tempo para percebê-la, uma sensibilidade, uma ética que se desenha mais no deslocamento respeitoso do pesquisador em direção ao tema, do que no tentar trazê-lo estrategicamente para junto de si. Tema e pesquisador carecem construir entre si um jogo de semelhanças tal qual a borboleta com seu menino - ou seria do menino com sua borboleta? O menino a capturar a borboleta? A borboleta a capturar o menino? É o encantamento e o desejo da captura, é essa alteridade desenhada de dentro do tema, lapidada pelo tema, que segreda ao pesquisador a metodologia mais fértil para o diálogo, os espaços e tempos necessários para o tipo de diálogo que o tema exige ou requer. A metodologia nasce quando o pesquisador retém a fisionomia do seu tema e já dialoga com ele num idioma comum.

Recebido em 26 de agosto de 2020 Aprovado em 9 de setembro de 2020

\section{Notas}

1 Todas as teses e dissertações aqui apresentadas encontram-se disponíveis no site: <http://www.proped.pro.br>.

2 Fiosiognomias da Infância: experiências cotidianas, alteridades e deslocamentos. Projeto financiado pelo Programa Prociência UERJ/FAPERJ e pelo Edital de Produtividade em Pesquisa do CNPq. Resulta desse projeto o livro Infância Crônica, reunindo 35 crônicas escritas a partir de observações de pesquisa.

\section{Referências}

BAKHTIN, Mikhail. Estética da Criação Verbal. São Paulo: Martins Fontes, 2003.

BAKHTIN, Mikhail; VOLOCHINOV, Valentin. Marxismo e Filosofia da Linguagem. Rio de Janeiro: HUCITEC, 2006.

BENJAMIN, Walter. Sobre el Programa de la Filosofia Futura y Otros Ensayos. Caracas: Monte Ávila, 1970.

BENJAMIN, Walter. Obras escolhidas vol I - arte e política, magia e técnica. São Paulo: Brasiliense, 1985.

BENJAMIN, Walter. Obras escolhidas vol II - rua de mão única. São Paulo: Brasiliense, 2005.

BENJAMIN, Walter. Passagens. Belo Horizonte: Editora da UFMG, São Paulo: Imprensa Oficial do Estado de São Paulo, 2006.

BENJAMIN, Walter. Reflexões sobre a Criança, o Brinquedo e a Educação. São Paulo: Editora Duas Cidades; Editora 34, 2009.

BOENAVIDES, William Moreno. Sobre o Conceito de 'Tema' em Marxismo e Filosofia da Linguagem. Organon, Porto Alegre, v. 30, n. 59, p. 211-224, jul./dez. 2015.

CASTRO, Cláudia Maria de. A Arte de Caçar Borboletas. In: JOBIM E SOUZA, Solange; KRAMER, Sonia. Política, Cidade, Educação: itinerários de Walter Benjamin. Rio de Janeiro: Contraponto e Ed. PUC-Rio, 2009.

LÖWY, Michael. Walter Benjamin: aviso de incêndio: uma leitura das teses 'Sobre o conceito de história'. São Paulo: Boitempo, 2005. 
MACEDO, Nélia Mara Rezende. ‘Você tem face?' Sobre Crianças e Redes Sociais Online. 2014. 296 f. Tese (Doutorado em Educação) - Programa de Pós-Graduação em Educação, Universidade do Estado do Rio de Janeiro, Rio de Janeiro, 2014.

SANTOS, Núbia de Oliveira. Quando menos é mais! A criança e seu aniversário. 2013. 265 f. Tese (Doutorado em Educação) - Programa de Pós-Graduação em Educação, Universidade do Estado do Rio de Janeiro, Rio de Janeiro, 2013.

SCHUBSKI, Cecília de Miranda et al. Sob o Signo da Alteridade: sob o signo da alteridade: diversidade e participação na pesquisa com crianças. In: SEMINÁRIO DE GRUPOS DE PESQUISA SOBRE CRIANÇAS E INFÂNCIAS, 6., 2018, Belém. Anais... Belém: Universidade Federal do Pará, 2018.

SILVA, João Marcelo Lanzilotti. 'Vamos montar uma banda?': um olhar sobre os processos de criação musical de crianças. 2015. $198 \mathrm{f}$. Tese (Doutorado em Educação) - Programa de Pós-Graduação em educação, Universidade do Estado do Rio de Janeiro, Rio de Janeiro, 2015.

SILVA, Perseu Pereira. Fisionomias das Infâncias Contemporâneas: crianças em vídeos virais. 2018. 186f. Dissertação (Mestrado em Educação) - Programa de Pós-Graduação em Educação, Universidade do Estado do Rio de Janeiro, Rio de Janeiro, 2018.

VENAS, Raíza Moreira Martins. Tem criança na Roda! Percepções da Infância nas Rodas de Samba. 2019. 79f. Dissertação (Mestrado em Educação) - Programa de Pós-Graduação em Educação, Universidade do Estado do Rio de Janeiro, Rio de Janeiro, 2019.

VENAS, Raíza; RIBES, Rita. Infância Crônica. Rio de Janeiro: NAU Editora, 2019. VIOLA, Paulinho da. Argumento. Rio de Janeiro: EMI, 1975. 1 CD (38 min.).

Rita Ribes Pereira é licenciada em Filosofia pela Universidade Federal de Pelotas e Doutora em Ciências da Educação pela Pontifícia Universidade Católica do Rio de Janeiro. Professora da Faculdade de Educação da Universidade do Estado do Rio de Janeiro. Coordenadora do Grupo de Pesquisa Infância e Cultura Contemporânea. Procientista UERJ/FAPERJ e Bolsista de Produtividade do CNPq.

ORCID: http://orcid.org/0000-0002-8605-3394

E-mail: ritaribes@uol.com.br

Editora-responsável: Fabiana Amorim Marcello

Este é um artigo de acesso aberto distribuído sob os termos de uma Licença Creative Commons Atribuição 4.0 Internacional. Disponível em: <http:// creativecommons.org/licenses/by/4.0>. 